\title{
Study on Nugget Development in RSW Process with Flat Tip Cylindrical Electrode
}

\author{
Shaik Shafee ${ }^{1}$, Dr. B. Balu Naik², Dr. K. Sammaiah ${ }^{3}$, Dr.Mohd. Mohinoddin ${ }^{4}$ \\ ${ }^{1}$ Research Scholar, JNTUH, Kukatpally, Hyderabad-500 085, India. \\ ${ }^{2}$ Principal \& Professor, JNTUM, Manthani, Kareem Nagar Dt., A.P. \\ ${ }^{3}$ Professor, Department of Mechanical Engineering, Aeronautical Engineering College, Dundigal, R.R. Dt., \\ A.P. \\ ${ }^{4}$ Associate Professor, Department of Mechanical Engineering, M.J. College of Engineering \& Technology, \\ Hyderabad-500034, India
}

\begin{abstract}
The objective of this work is to develop a numerical model of the resistance spot welding process with a flat cylindricallower electrode, enabling to predict accurately the spot weld geometry development. A $2 D$ axisymmetric electro-thermo-mechanical finite element (FE) model is developed to study the effect of spot welding parameters on nugget size using ANSYS commercial software package. The nugget formation processes at the various welding conditions were investigated by both experimental measurement and FEM simulation. In order to improve the accuracy, temperature dependent properties of material are taken into account during the simulation. Experiments were carried out to verify the preciseness of simulation. Two different thicknesses of austenitic stainless steel sheets were used in the study. The FE predicted weld nugget sizes agreed well with the experimental results. Overall, the present work indicated that finite element analysis can be very useful as an off-line observation tool to estimate the influence of welding parameters on the welding quality and to predict or improve the welding quality.
\end{abstract}

Key words:Resistance spot welding, Austenitic stainless steel, Finite element method, Nugget.

\section{Introduction}

Resistance spot welding was inventedin 1877 by Elihu Thomson and has beenwidely used since then as a manufacturingprocess for joining sheet metal. It is still the dominant process for sheet metal joining in the automotive industry. Its main advantage is thatit easily enables further automation and robotic enhancements leading to an increased production rate. The main goal of the RSW process is to generate heat quickly at the contact point between the sheet metals andto minimize the amount of heat dissipated by driving it from the metal plates to the electrodes as well as for theregions in the periphery of the Heat Affected Zone (HAZ).The high thermal conductivity of the electrodes provides a method to control the nugget formation and cool-down by conducting heat from the workpiece.In this study a larger diameter flat tipped cylindrical bottom electrode is used to provide more mechanical support, larger surface area for heat dissipation, which helps to improve the weld quality and restricts the formation of dimples to only one side of the spot welded joint. Thechange of electrode shape induces some new characteristicsabout nugget formation during resistance spot welding, whichshould be investigated. The nugget formation of resistancespot welding with cylindrical electrodes was simulated by ANSYS commercial software.

Resistance spot welding is a complicated process, which involves interactions of electrical, thermal, mechanical and metallurgical phenomena. The materials to be joined are brought together under pressure by a pair of electrodes. A high electric current passes through the workpieces between the electrodes. Due to contact resistance and Joule heating, a molten weld nugget is formed in the workpieces. The workpieces are joined as solidification of the weld pool occurs. Force is applied before, during and after the application of welding current, to maintain the electric current continuity and to provide the pressure necessary to prevent expulsion.

Some works have already been carried out on the modeling of spot welding process and study the effect of parameters on nugget size.Nied-1984[1] introduced an electrically, thermally, and structurally coupled axisymmetric model considering temperature-dependent properties and Joule heating. The displacements and stress distributions of the electrode and workpiece were illustrated. However, temperature dependency of contact resistance was not considered. Gould-1987 [2] measured the nugget growth using a metallographic technique. A one-dimensional thermal model, which accounted for heat of fusion, contact resistance, and convection by qualitatively increasing the effective thermal conductivity in the liquid, was developed for comparisons. The differences between the predicted and measured nugget thicknesses and the nugget growths were suggested to be due to radial heat losses and under estimation of the heat generation at the faying surface.

Cho and Cho-1989 [3] presented a theoretical basis for thermal behaviour of resistance spot welding. Finite difference models were developed to predict the temperature and voltage distributions during nugget 
formation, incorporating the thermal-electrical interaction at the faying surfaces. Tsai-1991, 1992 [4-5] created a two-dimensional axisymmetric model using ANSYS to perform some parametric studies on the spot welding process. In the finite element analysis procedure, the temperature-dependent contact resistance and material properties were taken into account. Nugget growth was presented under various welding conditions.

Feulvarch E-2004, 2006 [6-7] presented a finite element formulation to measure the interface contact properties. It was shown that the calculated nugget appears earlier. It was also noticed that the nugget grows faster across the thickness. Hou-2007 [8] developed a 2D axisymmetric thermo-elastic-plastic FEM model using ANSYS software package. The objective of this study was to investigate the behaviour of the mechanical features during the RSW process. They studied the distribution and change history of the contact pressure at both the faying surface and the electrode-workpiece during spot welding. The deformation of the weldment and the electrode displacement due to the thermal expansion and contraction were also calculated. They observed that the electrode displacement has a direct correlation with the nugget formation, and suggested utilizing this parameter for quality monitoring and process control in RSW. Rogeon-2008 [9] determined the contact conditions at the interfaces electrode-sheet and sheet-sheet. They measured electrical contact resistances depending to the temperature and under pressure in their work.

Shamsul and Hisyam-2007 [10] studied the RSW of austenitic stainless steel type 304. They found that the nugget size does not influence the hardness distribution. In addition, increasing welding current does not increase the hardness distribution. Lately, Eisazadeh-2010 [11] developed an incremental finite element model for parametric study of nugget size in resistance spot welding process. They used published experimental data to verify their model, and investigated effects of contact resistance and electrode force on nugget size and shape. They found that with increasing electrode force, nugget size reduces due to decreasing contact resistance.

It is well known that nugget size is the key factor that influences the welding quality. American Welding society (AWS), American National Standards Institute (ANSI) and Society of Automotive Engineers (SAE) [12-14] jointly recommended the size of the spot weld nugget diameter for steel according to the following equation $d=4 \sqrt{t}$. Where ' $d$ ' and ' $t$ ' are the nugget diameter and sheet thickness in ' $m m$ ' respectively. However to ensure an acceptable weld quality and confidence, understanding the mechanism of heat distribution, and weld formation are one of the key issues to develop an appropriate welding conditions. Due to a large number of pertinent parameters; such as the geometry and materials of sheet products, electrodes, and dynamic characteristics of process and welding machines, it is therefore a difficult task to manage the time-to market of new products, especially when joining complex geometries and new metal combinations. The development of sheet combinations and optimization of process parameters setting in the industry are strongly dependent on the personal experience of welding engineers, which is often based on a trial-and-error method. This involves a great number of running-in experiments with real welding, destructive tests, and metallographic studies. The advantage of applying numerical modelling for resistance welding processes is obvious, especially for joining complex geometries and novel metal combinations. Recent advanced numerical modelling can be therefore an approach to disclose the internal physical phenomena and a promising predictive tool for an innovative resistance welding process.

In this study, a two-dimensional axisymmetric finite element model with contact elements has been developed to investigate the distribution of temperature and nugget formation during resistance spot welding as well as to study the effects of welding parameters such as applied welding current,electrode force and welding time on the nugget size. The results of finite element analyses are compared with the experimental measurements. The contribution of this work contains following three parts:

[1] The entire welding process was viewed as a coupled electrical-thermal-mechanical process.

[2] Development of an effective finite element model to describe the resistance spot welding.

[3] Conduct extensive experiments and result data analysis to verify the effectiveness of this finite element model.

\section{Experimental Procedure}

The material used in this study is SS 304 austenitic stainless steels are themost common and familiar types of stainlesssteel. They are most easily recognized as nonmagnetic.They are extremely formable and spot weldable, and they can be successfully usedfrom cryogenic temperatures to the red-hot temperaturesof furnaces and jet engines. Austeniticstainless steel metal sheets of thickness of $0.8 \mathrm{~mm}$ and 1.0 mmand the length of the coupons is $80 \mathrm{~mm}$ and width of the coupons is $40 \mathrm{mmfor}$ both the lap sheet thicknesses. The experiments involved joining of two layer of sheet metal of $0.8 \mathrm{~mm}$ and $1.0 \mathrm{~mm}$ thickness were chosen as the base metal for this study.The chemical composition of the investigated steels is given in Table 1. Spot welding was performed using a calibrated $15 \mathrm{kVA}, \mathrm{AC}$ pedestal type resistance spot welding machine operating at $415 \mathrm{~V}, 50 \mathrm{~Hz}$, controlled by a Programmable Logic Controller (PLC). Spot Welding was conducted using an upper electrode of $45^{\circ}$ truncated cone with a $10 \mathrm{~mm}$ face diameter and lower electrode of flat tipped cylindrical in shape with a face diameter of $30 \mathrm{~mm}$.To investigate the effect of Electrode force, welding time and welding current on 
nugget size, series of test-specimens of the same material wasspot welded, by varying spot weld parameters for two lap sheets as per the details in table 2.The arrangements of spot weld coupons before and after spot welding of both two lap sheets of different thicknesses are shown in figure1 and 2.

\begin{tabular}{|c|c|c|c|c|c|c|c|c|}
\hline \multirow{2}{*}{ Designation } & \multicolumn{7}{|c|}{ Maximum percentage of alloying elements } \\
\cline { 2 - 9 } & $\mathrm{C}$ & $\mathrm{Cr}$ & $\mathrm{Ni}$ & $\mathrm{Mn}$ & $\mathrm{Si}$ & $\mathrm{P}$ & $\mathrm{S}$ & $\mathrm{N}$ \\
\hline $\mathrm{SS} \mathrm{304}$ & $\leq 0.07$ & 17.0 to 19.5 & 8.0 to 10.5 & $\leq 2.0$ & $\leq 0.045$ & $\leq 0.045$ & $\leq 0.015$ & $\leq 0.11$ \\
\hline
\end{tabular}

Table 1:Chemical composition SS 304 Austenitic stainless steel

\begin{tabular}{|c|c|c|c|c|}
\hline \multirow{2}{*}{$\begin{array}{l}\text { S. } \\
\text { No. }\end{array}$} & \multirow{2}{*}{$\begin{array}{c}\text { Thickness of the } \\
\text { sheets in } \\
\text { mm }\end{array}$} & \multicolumn{3}{|c|}{ Spot Welding Parameters } \\
\hline & & $\begin{array}{l}\text { Welding Current in } \\
\mathrm{kA}\end{array}$ & $\begin{array}{c}\text { Electrode Force } \\
\mathrm{kN}\end{array}$ & $\begin{array}{c}\text { Welding time in } \\
\text { cycles }\end{array}$ \\
\hline 1. & \multirow{4}{*}{$\begin{array}{c}0.8 \mathrm{~mm} \\
(80 \mathrm{~mm} \times 40 \mathrm{~mm})\end{array}$} & 3.0 & 1.6 & 75 \\
\hline 2. & & 3.5 & 1.8 & 100 \\
\hline 3. & & 4.0 & 2.0 & 125 \\
\hline 4. & & 4.5 & 2.2 & 150 \\
\hline 5. & \multirow{4}{*}{$\begin{array}{c}1.0 \mathrm{~mm} \\
(80 \mathrm{~mm} \times 40 \mathrm{~mm})\end{array}$} & 3.0 & 1.6 & 75 \\
\hline 6. & & 3.5 & 1.8 & 100 \\
\hline 7. & & 4.0 & 2.0 & 125 \\
\hline 8. & & 4.5 & 2.2 & 150 \\
\hline
\end{tabular}

Table 2:RSW Parameters used for investigating their effect on Nugget size for two lap sheets

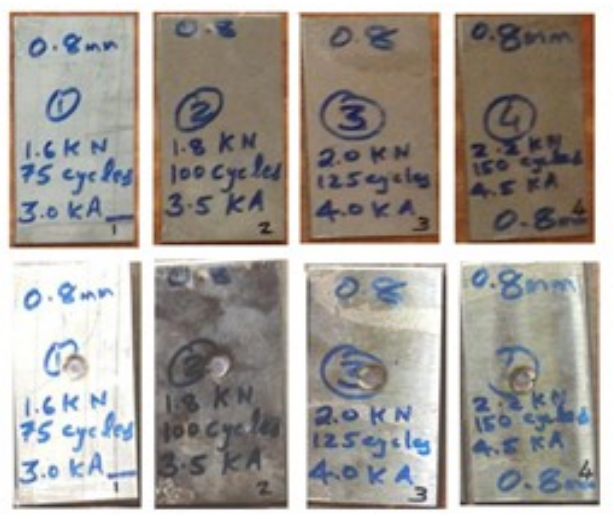

Fig.1

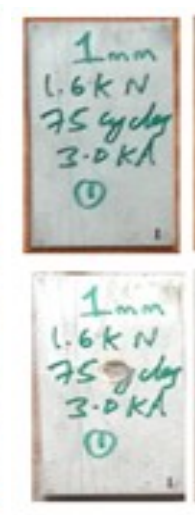

(1)

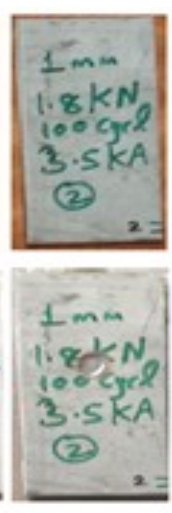

2

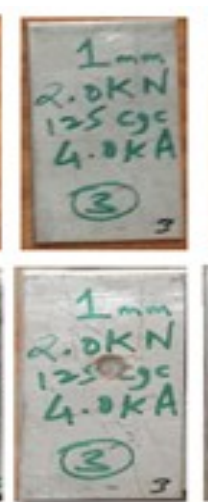

Fig.2

III. Simulation of SS 304 Austenitic Stainless Steel-RSW Via FEM

The objective of this study is to develop a multi-coupled method to analyse the thermal and mechanical behaviours of RSW process, reduce the computing time with the minimum loss of accuracy and get more adequate information of the process, improve the quality monitoring and process control of RSW. Apractical model of Resistance spot welding process for two lap sheetsis used.Welding current (I) and Welding force (F) applied to the electrodes are electrical load and mechanical load, respectively. The thermal boundary condition, electrical boundary condition (current boundary and potential) and displacement boundary conditions are also shown in these figures $3 \& 4$. As simply described in the above sections, the spot welding process couples electrical field, thermal field and mechanical field including the contact states at the interfaces between worksheets and electrodes.

\section{Governing Equations}

The RSW process can be simulated as axisymmetric problem. The governing equation for as axisymmetric transient thermal analysis is given by:

$$
\frac{\partial}{\partial r}\left(k \frac{\partial T}{\partial r}\right)+\frac{\partial}{\partial z}\left(k \frac{\partial T}{\partial z}\right)+\frac{k}{r} \frac{\partial T}{\partial r}+q_{V}=\rho C \frac{\partial T}{\partial t}(1)
$$

It is convenient to introduce cylindrical coordinates to solve the problem. Assumingsymmetry of the processes with respect to the electrode axis it is possible to reduce thenumber of dimensions to two without loss of generality. Where ' $\mathbf{r}$ ' and ' $\mathbf{z}$ ' are radial and axial coordinates and ' $\boldsymbol{\rho}$ ' is the density of the material; ' $\mathbf{C}$ ' is the specific heat capacity; ' $\mathrm{T}$ ' is the temperature as a function of coordinates and time; ' $\mathrm{t}$ ' is the time; ' $\mathbf{k}$ ' is the thermal conductivity; and $\mathbf{q}_{\mathbf{v}}$ is the rate of internal heat generation per unit volume. All the material properties are considered to be temperature dependent.

The thermal boundary conditions can be decomposed from the nonlinear isotropic Fourier heat flux constitutive relation:

$$
\mathbf{q}=-\mathbf{k} \nabla \mathbf{T}(2)
$$


On the boundary surface, there is

$$
\mathbf{q}=-\mathbf{k} \frac{\partial \mathbf{T}}{\partial \mathbf{n}}(3)
$$

Where ' $\mathbf{q}$ ' is the heat flux through the boundary surface; ' $\mathbf{n}$ ' is the outward normal to the surface.

The governing equation of the electrical analysis is

$$
\frac{\partial}{\partial r}\left(C_{e} \frac{\partial \emptyset}{\partial r}\right)+\frac{C_{e}}{r} \frac{\partial \emptyset}{\partial r}+\frac{\partial}{\partial z}\left(C_{e} \frac{\partial \emptyset}{\partial z}\right)=0(4)
$$

Where, ' $\mathbf{C}_{\mathbf{e}}$ ' is the electrical conductivity; ' $\boldsymbol{\phi}$ ' is the electrical potential.

The coupled thermal electrical problem is solved by the following matrix equation:

$$
\left[\begin{array}{cc}
{\left[\mathbf{C}^{\mathbf{t}}\right]} & {[\mathbf{0}]} \\
{[\mathbf{0}]} & {[\mathbf{0}]}
\end{array}\right]\left\{\begin{array}{l}
\{\dot{\mathbf{T}}\} \\
\dot{\mathbf{V}}\}
\end{array}\right\}=\left[\begin{array}{cc}
{\left[\mathbf{K}^{\mathbf{t}}\right]} & {[\mathbf{0}]} \\
{[\mathbf{0}]} & {\left[\mathbf{K}^{\mathbf{v}}\right]}
\end{array}\right]\left\{\begin{array}{l}
\{\mathbf{T}\} \\
\{\mathbf{V}\}
\end{array}\right\}=\left\{\begin{array}{c}
\{\mathbf{Q}\} \\
\{\mathbf{I}\}
\end{array}\right\}
$$

Where $\left[\mathrm{C}^{\mathrm{t}}\right]$ is the thermal specific heat matrix; $\left[\mathrm{K}^{\mathrm{t}}\right]$ the thermal conductivity matrix; $\left[\mathrm{K}^{\mathrm{v}}\right]$ the electric coefficient matrix; $\{\mathrm{T}\}$ temperature vector; $\{\mathrm{V}\}$ the electric potential vector; $\{\mathrm{Q}\}$ the heat flow vector; and $\{\mathrm{I}\}$ is the current vector.

For the structural analysis, the stress equilibrium equation is given by

$$
\boldsymbol{\nabla \sigma}\{\mathbf{r}, \mathbf{t}\}+\mathbf{b}(\mathbf{r}, \mathbf{t})=\mathbf{0}
$$

Where ' $\boldsymbol{\sigma}$ ' is the stress; ' $\mathbf{b}$ 'is the body force, ' $\mathbf{r}$ 'is the coordinate vector.

The constructive equation of the material based on the thermo-elastic-plastic theory is given by

$$
\begin{aligned}
& \mathbf{d}\{\boldsymbol{\sigma}\}=[\mathbf{D}] \mathbf{d}\{\boldsymbol{\varepsilon}\}-\{\mathbf{C}\} \mathbf{d} \mathbf{T} \\
& \{\mathbf{C}\}=-\left[\mathbf{D}^{\mathbf{e}}\right]\left(\{\boldsymbol{\alpha}\}+\frac{\partial\left[\mathbf{D}^{\mathbf{e}}\right]^{-\mathbf{1}}}{\partial \mathbf{T}}\{\boldsymbol{\sigma}\}\right)
\end{aligned}
$$

Where $\{\sigma\}$ is the stress vector; [D] is the elastic-plastic matrix; $\{\varepsilon\}$ is the strain vector; $\left[\mathrm{D}^{\mathrm{e}}\right]$ is the elastic matrix; and $\{\alpha\}$ is the coefficient of thermal expansion.

\section{Modeling and Parameters}

Figure $3 \& 4$ illustrates the 2-dimensional axisymmetric FEA model of RSW process built in ANSYS program, where $\mathbf{X}$ and $\mathbf{Y}$ represent the faying surface and the axisymmetric axis respectively.Its corresponding dimensions for $0.8 \mathrm{~mm}$ and $1.0 \mathrm{~mm}$ thickness sheets are tabulated in Table 4.

2-D axisymmetric model of twolap sheets joining with the application of flat cylindrical lower electrode is constructed. Both electrical-thermal and mechanical contact elements are specially treated at the electrode-to-sheet and sheet-to-sheet interface. The imposed boundary conditions and representative mesh model can be found in Fig.4. It is worth noting that in the mechanical analysis, elements of type "Plane 42" and in the electro-thermal model, elements of type "Plane 67", having capabilities of thermal, electrical and thermalelectrical analyses were used. There were three contact areas in the model, two contact areas representing the electrode-sheet interface and one representing the sheet-sheet interface. The contact pair elements "Targe169" and "Conta171" were employed to simulate the contact areas. Contact occurs when the element surface penetrates one of the target segment elements (TARGE169) on a specified target surface. Any translational or rotational displacement, forces, moments, temperature, voltage and magnetic potential can be imposed on the target segment element.In the finite element analysis 2507 elements and 8051 nodes for $0.8 \mathrm{~mm}$ thickness plate and 2635 elements and 8439 nodes for $1.0 \mathrm{~mm}$ thickness plate have been employed.

In each analysis, the model is meshed using contact elements as shown in fig. 4 the solid element is employed to simulate the coupled interaction between the sheets and electrodes. In order to correctly couple and transfer the data the model must have identical mesh both in the electrical -thermal analysis and in the thermoelastic and plastic analysis. Whereas the element types are different or have different degree of freedom options as shown in Table 5.

\begin{tabular}{|c|c|c|c|c|c|c|c|c|}
\hline Dimensions & US $=$ LS & AC=BD & UA & UH & UF & ED & LL & UB \\
\hline Value $(\mathrm{mm})$ & 0.8 or 1.0 & 15 & 12 & 30 & 8 & 3 & 16 & $45^{\circ}$ \\
\hline
\end{tabular}

$$
\text { Table } 4
$$




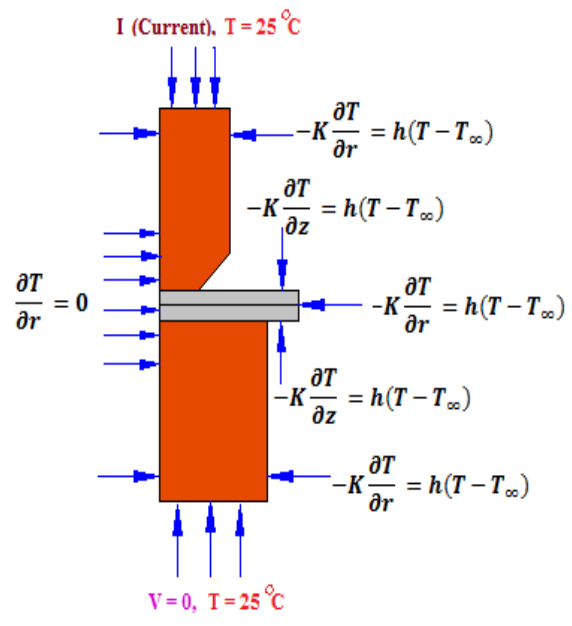

(3a)

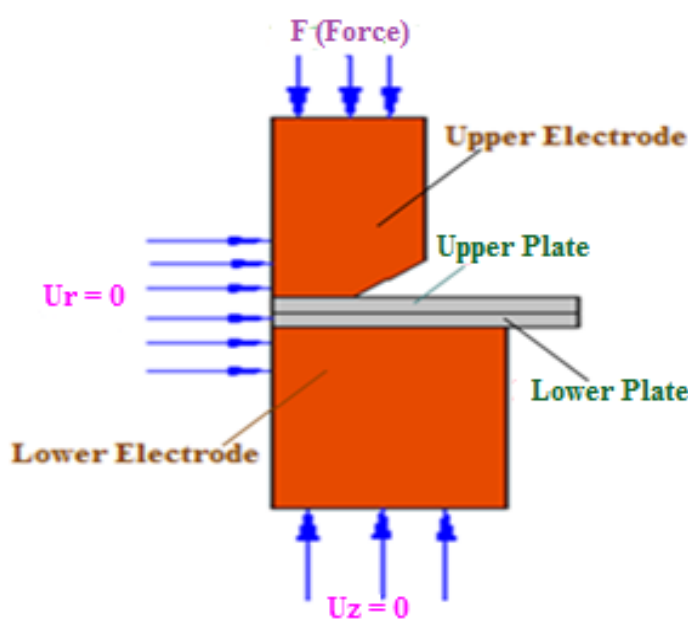

(3b)

Fig. 3 a, b, c:The Computational Domain and Boundary Conditions

\section{Interface Elements}

The contact between an electrode and a sheet or between two sheets was modeled by the interface elements Ma and Murakawa, 2009 [15] as shown in Fig. 5. If the strain ' $\boldsymbol{\varepsilon}_{\mathbf{n}}$, of the interface element in the normal direction ' $\mathbf{n}$ ' of the contact interface is larger than -1.0 , the state of the interface is the non-contact state. In the initial state and non-contact state, the electrical conductivity ' $\mathbf{C}_{\mathbf{e}}$ 'thermal conductivity ' $\mathbf{k}$ ' and Young's modulus ' $\mathbf{E}$ ' will be zero. This means that current flow through the interface element and heat generation will be zero at the inter-face element. If the strain ' $\boldsymbol{\varepsilon}_{\mathbf{n}}$ ' of the interface element in the normal direction $\mathbf{n}$ of the contact interface is equal to or less than -1.0 , the state of the interface is the in-contact state. In the contact state, the electrical conductivity $\mathbf{C}_{\mathbf{e}}$ thermal conductivity $\mathbf{k}$ and Young's modulus $\mathbf{E}$ will be a given value, respectively. This means that current flows through the interface element and heat is generated at the interface element. In the contact state, the interface element has a strong stiffness. The material properties of interface contact elements used for the analysis of the electrical field, thermal field and mechanical field are independent from worksheets and electrodes. Therefore, the contact resistance can also be considered if it is known. The formulation of the interface element has no much difference from the ordinary element except the material properties and their changes with the contact states. Therefore, it is relatively simple and reliable to deal with the electrical-thermalmechanical contact between two faces for the spot welding process simulation.
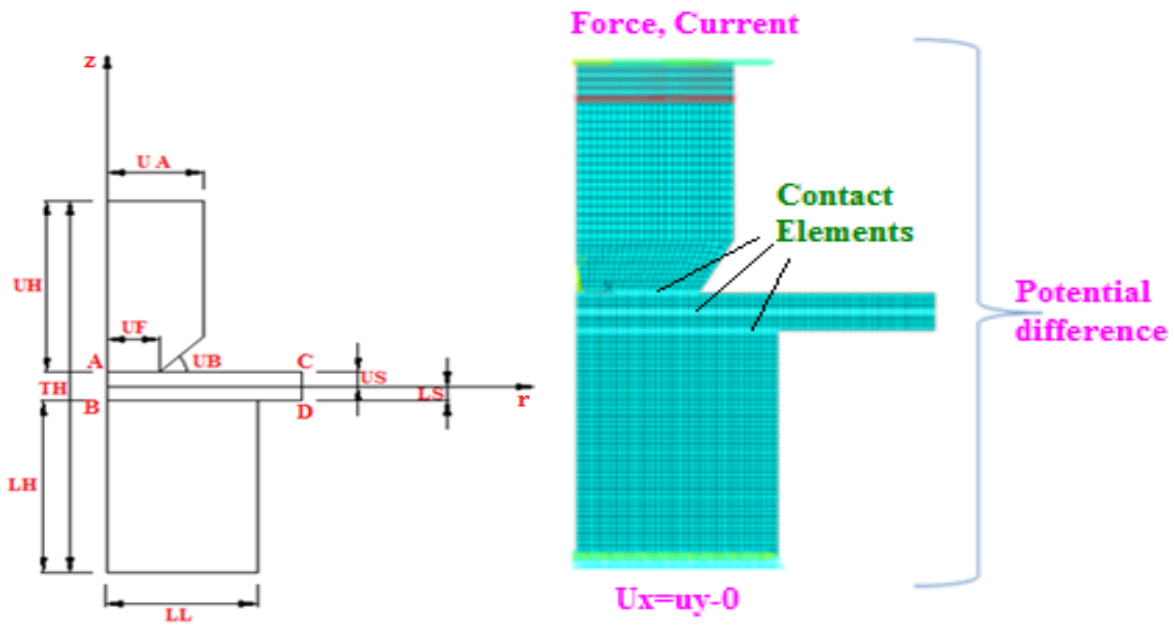

(3c)

Fig.4:The FEA model for two lap sheets

Prior to welding, the electrical initial conditions are set equal to zero, while the temperature of entire structure is maintained at temperature of $25^{\circ} \mathrm{C}$. During the welding cycle, the welding current is applied at the top of the upper electrode and zero potential is imposed at the bottom surface of the lower electrode. Consequently, the current flows from the upper electrode, passes through work piece and terminates at the 
bottom annular section of the lower electrode. Both force and current are modelled from practical welding signals and defined as a time-dependent function.

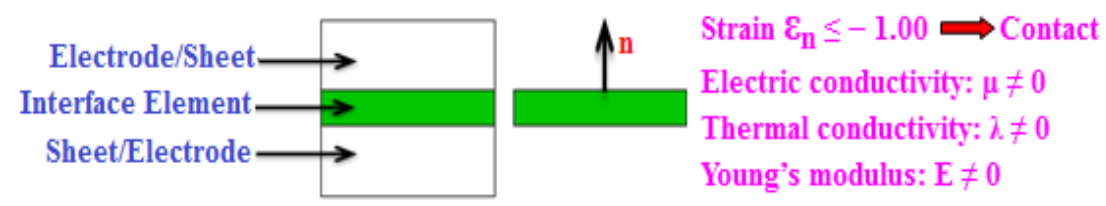

Fig.5: Contact elements

\begin{tabular}{|c|c|c|}
\hline Analysis & Electrical-Thermal & Thermo-Elastic-Plastic \\
\hline Solid & PLANE 67 & PLANE 42 \\
\hline Contact element type & CONTA 171/TARGE169 & CONTA 171/TARGE169 \\
\hline $\begin{array}{c}\text { Degree of freedom } \\
\text { (for contact element) }\end{array}$ & TEMP, VOLT & UX, UY \\
\hline
\end{tabular}

Table 5: Element types and degree of freedom options

\section{Mechanical Boundary Conditions}

Uniform load was applied at the top of the copper electrode during welding and holding cycle. The electrode was removed at the end of the holding cycle. At the faying surface between the electrode and the workpiece, a conta 171 element was used. At the faying surface between workpiece and workpiece, the vertical displacement of the part of faying surface under electrode was set to zero, and a subroutine program was used to determine if the other part of faying surface is under contact or not. If some nodes are under contact and are under pressure stress, a zero vertical displacement was applied here.

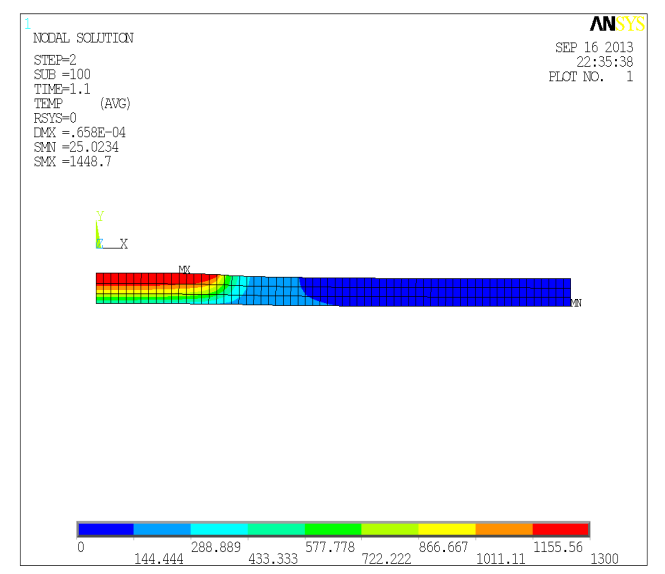

Fig. 6a

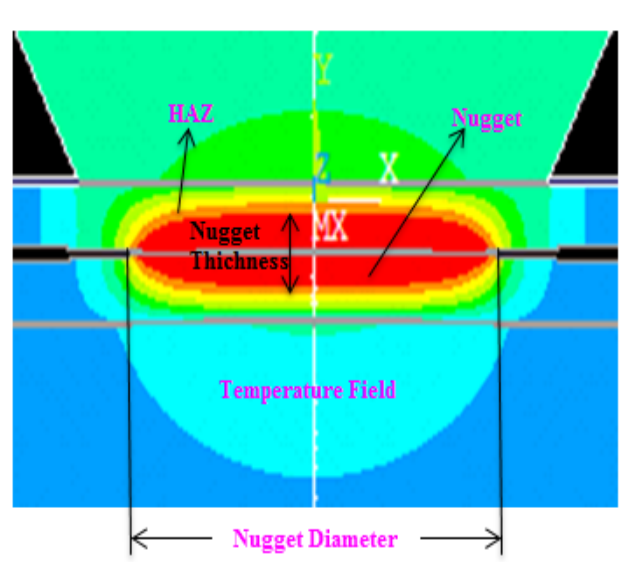

Fig. 6b

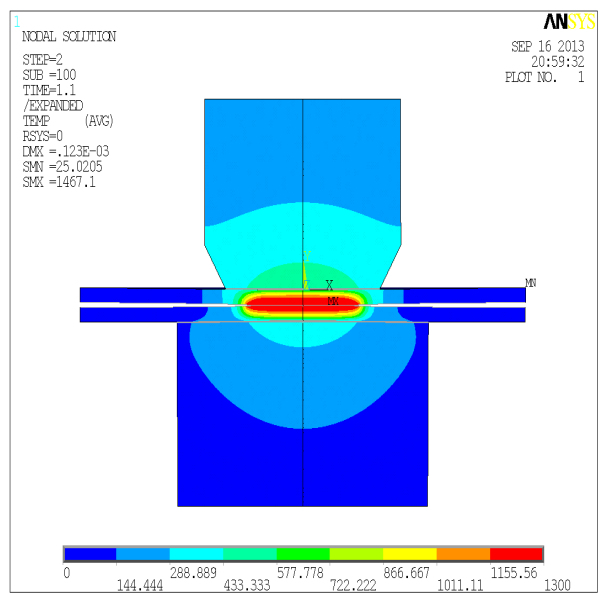

Fig. 6c

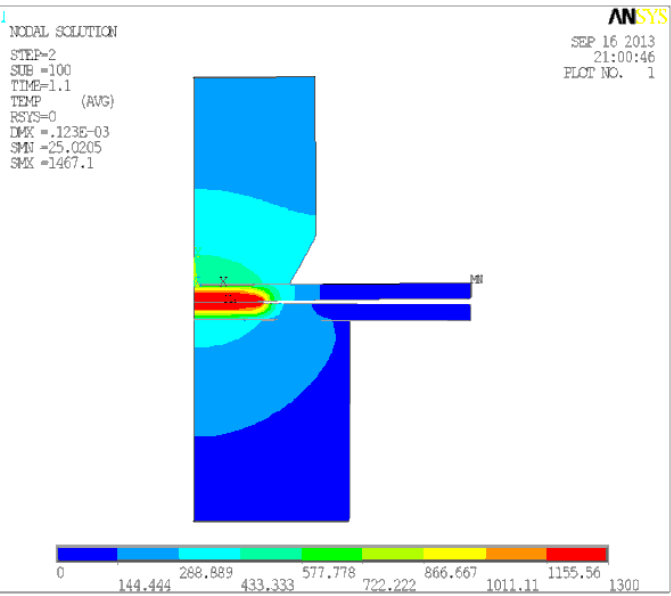

Fig. 6d 


\section{Results and Discussions}

In this study, a coupled thermal-electro-mechanical finite element model is presented for predicting temperature distribution and spot nugget size in a spot welded steel joint. By providing the necessary information and boundary conditions, simulations were performed for three combined analysis during different stages of welding cycle. The thermal, electrical and mechanical properties of electrode and work piece are given in Table 6 and Table 7. Because the materials are subjected to a wide range of temperatures, most of these properties are considered as temperature dependent.To verify the simulation results, weld experiments were done under the same welding conditions. Comparisons were made between simulation and experimental results of the nugget diameter and they are shown in the Fig.8. There is generally good agreement between simulation and experimental results for most of the experiments for two lap sheets spot weld.Fig. 3 shows the geometry used for the modeling purpose.

It is observedthat the highest temperature is always at the center of faying surfaceduring the whole RSW process. In addition, the temperatureof the faying surface is higher than that of the electrodesheetinterface. The region which experiences the melting temperature during welding process is determined as weld nugget. Fig. 7 shows temperature distribution of the weldment at the end of welding cycles and the nugget size determined for parameters of sample 1and Fig. 6 shows nugget geometry details.

\begin{tabular}{|c|c|c|c|c|c|c|c|}
\hline \multirow[t]{2}{*}{$\begin{array}{l}\text { Temperature } \\
{ }^{\circ} \mathrm{C}\end{array}$} & \multicolumn{2}{|c|}{$\begin{array}{l}\text { Thermal conductivity } \\
\mathrm{J} / \mathrm{m} .{ }^{\circ} \mathrm{C} \\
\end{array}$} & \multicolumn{2}{|c|}{$\begin{array}{c}\text { Electrical resistivity } \\
\mu \Omega . \mathrm{m}\end{array}$} & \multirow{2}{*}{$\begin{array}{c}\text { Contact resistivity } \\
\Omega . \mathrm{m}^{2} \times 10^{-7} \\
\text { Faying surface }\end{array}$} & \multicolumn{2}{|c|}{$\begin{array}{c}\text { Specific Heat } \\
\mathrm{J} /\left(\mathrm{kg} .{ }^{\circ} \mathrm{C}\right)\end{array}$} \\
\hline & $\begin{array}{c}\text { Stainless } \\
\text { Steel }\end{array}$ & $\begin{array}{c}\text { Copper } \\
\text { Electrode }\end{array}$ & $\begin{array}{c}\text { Stainless } \\
\text { Steel }\end{array}$ & $\begin{array}{c}\text { Copper } \\
\text { Electrode }\end{array}$ & & $\begin{array}{c}\text { Stainless } \\
\text { Steel }\end{array}$ & $\begin{array}{c}\text { Copper } \\
\text { Electrode }\end{array}$ \\
\hline 20 & 14.6 & 390.3 & 0.604 & 26.4 & 2.38 & 462 & 397 \\
\hline 93 & & 380.6 & & 30.0 & 2.31 & & 402 \\
\hline 100 & 15.1 & & 0.702 & & 2.25 & 496 & \\
\hline 200 & 16.1 & 370.1 & 0.774 & 40.0 & 2.12 & 512 & 419 \\
\hline 300 & 17.9 & & 0.858 & & 1.93 & 525 & \\
\hline 316 & & 355.1 & & 50.5 & 1.79 & & 431 \\
\hline 400 & 18.0 & & 0.922 & & 1.31 & 540 & \\
\hline 427 & & 345.4 & & 61.9 & & & 440 \\
\hline 538 & & 334.9 & & 69.9 & 0.567 & & 465 \\
\hline 600 & 20.8 & & 1.001 & & & 577 & \\
\hline 649 & & 320 & & 80.0 & & & 477 \\
\hline 760 & & 315.5 & & 89.8 & 0.492 & & \\
\hline 800 & 32.2 & & 1.120 & & 0.417 & 604 & \\
\hline 871 & & 310.3 & & 94.8 & 0.342 & & \\
\hline 982 & & 305 & & 99.8 & & & 502 \\
\hline 1200 & & & 1.210 & & & 676 & \\
\hline 1300 & 33.7 & & 1.280 & & & 692 & \\
\hline 1480 & 120 & & & & & 700 & \\
\hline
\end{tabular}

Table 6: Thermal and electrical properties of the employed SS304 andcopper electrodes.

\begin{tabular}{|c|c|c|c|c|c|c|c|c|c|c|}
\hline \multirow[t]{2}{*}{$\begin{array}{l}\text { Temp- } \\
\text { erature } \\
{ }^{\circ} \mathrm{C}\end{array}$} & \multicolumn{2}{|c|}{$\begin{array}{l}\text { Young's } \\
\text { Modulus } \\
\mathrm{G} \mathrm{P}_{\mathrm{a}}\end{array}$} & \multicolumn{2}{|c|}{$\begin{array}{c}\text { Yield stress } \\
\mathrm{M} \mathrm{P}_{\mathrm{a}}\end{array}$} & \multicolumn{2}{|c|}{ Poisson's ratio } & \multicolumn{2}{|c|}{$\begin{array}{l}\text { Coefficient of thermal } \\
\text { expansion } \\
\left(\mathrm{C}-1 \times 10^{-5}\right)\end{array}$} & \multicolumn{2}{|c|}{$\begin{array}{l}\text { Density } \\
\mathrm{Kg} / \mathrm{m}^{3}\end{array}$} \\
\hline & $\begin{array}{c}\text { Stainless } \\
\text { Steel }\end{array}$ & $\begin{array}{c}\text { Copper } \\
\text { Electrode }\end{array}$ & $\begin{array}{c}\text { Stainless } \\
\text { Steel }\end{array}$ & $\begin{array}{c}\text { Copper } \\
\text { Electrode }\end{array}$ & $\begin{array}{c}\text { Stainless } \\
\text { Steel }\end{array}$ & $\begin{array}{c}\text { Copper } \\
\text { Electrode }\end{array}$ & $\begin{array}{c}\text { Stainless } \\
\text { Steel }\end{array}$ & $\begin{array}{c}\text { Copper } \\
\text { Electrode }\end{array}$ & $\begin{array}{c}\text { Stainless } \\
\text { Steel }\end{array}$ & $\begin{array}{c}\text { Copper } \\
\text { Electrode }\end{array}$ \\
\hline & 198.5 & 124 & 319 & & 0.294 & & 1.70 & 1.65 & 7900 & 8900 \\
\hline 93 & & 105 & & & & & & 1.67 & & \\
\hline 100 & 193 & & 279 & & 0.295 & & 1.74 & & 7880 & \\
\hline 200 & 185 & 93 & 238 & & 0.301 & & 1.80 & 1.71 & 7830 & \\
\hline 300 & 176 & & 217 & 83 & 0.310 & 0.32 & 1.86 & & 7790 & \\
\hline 316 & & 82 & & & & & & 1.75 & & \\
\hline 400 & 167 & & 198 & & 0.318 & & 1.91 & & 7750 & \\
\hline 427 & & 55 & & & & & & 1.78 & & \\
\hline 538 & & 38 & & & & & & 1.84 & & \\
\hline 600 & 159 & & 177 & & 0.326 & & 1.96 & & 7660 & \\
\hline 649 & & 25 & & & & & & 1.85 & & \\
\hline 760 & & 16 & & & & & & 1.89 & & \\
\hline 800 & 151 & & 112 & & 0.333 & & 2.02 & & 7560 & \\
\hline 871 & & 14 & & & & & & 1.93 & & \\
\hline 982 & & 7 & & & & & & & & \\
\hline 1200 & 60 & & 32 & & 0.339 & & 2.07 & & 7370 & \\
\hline 1300 & 20 & & 19 & & 0.342 & & 2.11 & & 7320 & \\
\hline 1480 & 10 & & 8 & & 0.388 & & 2.16 & & 7320 & \\
\hline
\end{tabular}

Table 7: Mechanical properties of the employed SS304 andcopper electrodes 


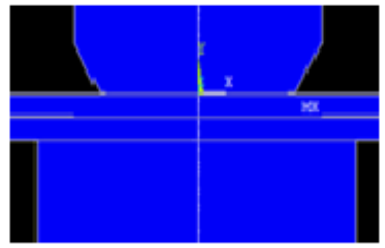

$\mathrm{t}=0.54 \mathrm{~s}$

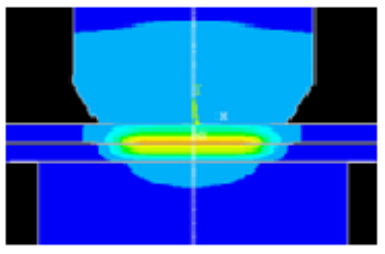

$\mathrm{t}=1.2 \mathrm{~s}$

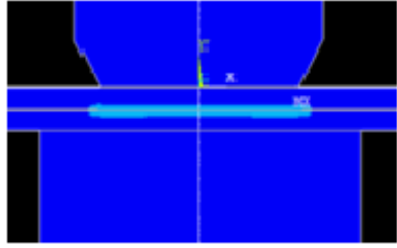

$\mathrm{t}=0.67 \mathrm{~s}$

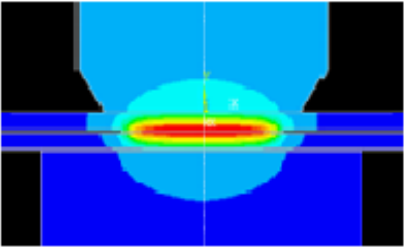

$\mathrm{t}=1.32 \mathrm{~s}$

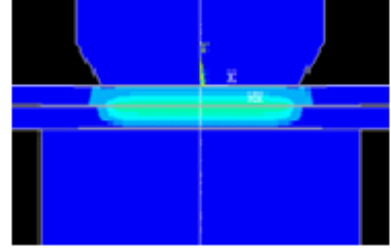

$\mathrm{t}=0.93 \mathrm{~s}$

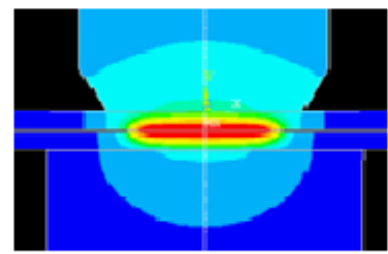

$\mathrm{t}=1.5 \mathrm{~s}$

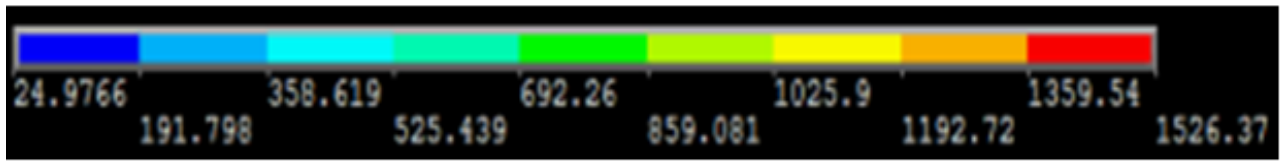

Fig.7
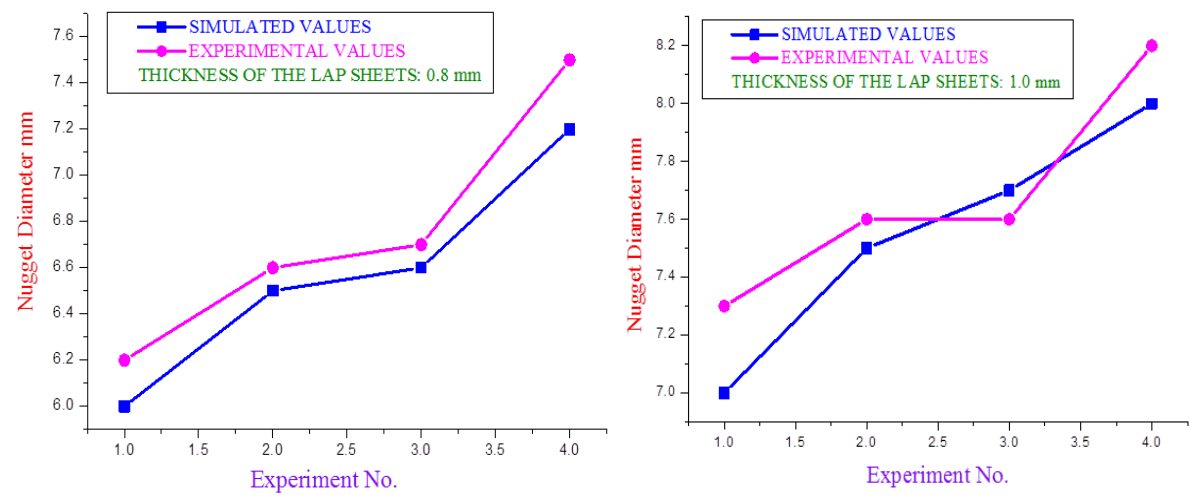

Fig. 8

\section{Conclusions}

A comprehensive simulation model using FEM for the analysis of resistance spot welding process has been developed. It has been observed that the finite element modeling of the resistance spot welding process can provide good simulation, if the model includes the electro-thermal-mechanical interaction and good temperature dependent material properties. This finite element model so developed can calculate most of the resistance spot welding responses in terms of nugget diameter, depth of penetration, the extent of heat affected zone, electrode face heating etc. Finally this FEM model will certainly help in optimizing process parameters combinations in any industrial application of resistance spot welding process.

A multi coupled electro-thermal and thermo-elastic-plastic analysis is developed and carried out on the transient thermal and mechanical behaviors of the RSW process. The results provide informationon the development of the weld nugget and thus predictthe welding quality prior to the actual welding process.Based on the ANSYS software, this multi coupled method can efficiently provide sufficient details of the RSW and benefit to the quality monitoring and process control of RSW. Finite element analysis can be very useful as an off-line observation tool to estimate the influence of welding parameters on the welding quality and to predict/improve the weld geometry.

\section{References}

[1] Nied, H.A., 1984. The finite element modeling of the resistance spot welding process. Welding J. 63, 123-132.

[2] Gould, J.E., 1987. An examination of nugget development during spot welding, using both experimental and analytical techniques. Welding J. 66, 1-10.

[3] Cho, H.S., Cho, Y.J., 1989. A study of thermal behavior in resistance spot welds. Welding J. 67, $236-244$.

[4] Tsai, C.L., Dai, W.L., Dickinson, D.W., Papritan, J.C., 1991. Analysis and development of real-time control methodology in resistance spot welding. Welding J. 69, 339-351. 
[5] Tsai, C.L., Jammel, O.A., Papritan, J.C., Dickinson, D.W., 1992. Modeling of resistance spot weld nugget growth. Welding J. 70, $47-54$.

[6] Feulvarch, E., Robin, V., Bergheau, J.M., 2004. Resistance spot welding simulation: a general finite element formulation of electrothermal contact conditions. J. Mater. Process. Technol. 153-154, 436-441.

[7] Feulvarch, E., Robin, V., Bergheau, J.M., 2006. Resistance spot welding process: experimental and numerical modeling of weld growth mechanisms with consideration of contact conditions. Numer. Heat Trans. Part A 49,345-367.

[8] Hou, Z., Kim, I., Wang, Y., Li, C., Chen, C.J., 2007. Finite element analysis for the mechanical features of resistance spot welding process. J. Mater. Process. Technol. 180, 160-165.

[9] Rogeon, P., Carre, P., Costa, J., Sibilia, G., Saindrenan, G., 2008. Characterization of electrical contact conditions in spot welding assemblies. J. Mater. Process. Technol. 195, 117-124.

[10] Shamsul, J.B., Hisyam, M.M., 2007. Study of spot welding of austenitic stainless steel type 304. J. Appl. Sci. Res. 3, $1494-1499$.

[11] Eisazadeh, H., Hamedi, M., Halvaee, A., 2010. New parametric study of nugget size in resistance spot welding process using finite element method. Mater. Des. J. 31, 149-157.

[12] ANSI/AWS/SAE/D8. 9-97, 1997. Recommended Practices for Test Methods and Evaluation the Resistance Spot Welding Behavior of Automotive Sheet Steels Materials. American Welding Society, Miami, FL, USA.

[13] ANSI/AWS/SAE/C1.1, 2000. Recommended Practice for Resistance Welding. American Welding Society, Miami, FL, USA

[14] ASTM E 340-00, Reapproved 2006. Standard Test Method for Macroetching Metals and Alloys. ASTM International, USA.

[15] Ma, N., Murakawa, H., 2009. Numerical and experimental study on nugget formation in resistance spot welding for high strength steel sheets in automobile body. Transactions of JWRI 38 (2), 19-24.

[16] Na, S.J., Park, S.W., 1996. A theoretical study on electrical and thermal response in resistance spot welding. Welding J. 75, 233241.

[17] Sun, M.A.T., 2003. Fundamental study of contact resistance behavior in RSW aluminum. The Ohio State University, Graduate School Ohio, p. 314.

[18] Khan, J.A.; Xu, L.; and Chao, Y.J. 1999. Prediction of nugget development during resistance spot welding using coupled thermalelectrical-mechanical model. Science and technology of welding and joining. Vol. 4, No.4: 201 to 207.

[19] Sun, X.; and Dong, P. Aug. 2000. Analysis of aluminum resistance spot welding processes using coupled finite element procedures. Welding research supplement: 215 -s to 221 -s.

[20] Brown, D. J. 1995. Computer simulation of resistance spot welding in aluminium. Welding Journal 74(12): 417 to 422. 